\title{
Changes of the corpus callosum in the parkinsonism
}

\author{
Amani Elfaki ${ }^{a}$, Murat Golpinar ${ }^{\text {a* }}$ İlkay Camlıdagb, Ersoy Kocabıcakc, Mert Nahir ${ }^{\mathrm{a}}$, Bunyamin Sahin $^{\mathrm{a}}$ \\ ${ }^{a}$ Department of Anatomy, Faculty of Medicine, Ondokuz, Mayls University, Samsun, Turkey \\ ${ }^{b}$ Department of Radiology, Faculty of Medicine, Ondokuz Mayı University, Samsun, Turkey \\ ${ }^{c}$ Department of Neurosurgery, Faculty of Medicine, Ondokuz Mayıs University, Samsun, Turkey
}

\section{ARTICLE INFO}

\section{* Correspondence to:}

Murat Golpinar

Department of Anatomy,

Faculty of Medicine,

Ondokuz Mayıs University,

Samsun, Turkey

e-mail:golpinarmurat@hotmail.com

\section{Keywords:}

Corpus callosum

Magnetic resonance imaging

Parkinsonism

Planimetry

Projection area fraction

\section{ABSTRACT}

The corpus callosum (CC) is the largest white-matter fibre tract in the brain that plays essential role in communicating sensory, motor and cognitive information between the two cerebral hemispheres. Corpus callosum area has been examined extensively in neurodegenerative diseases as a marker for cortical pathology and for differential diagnosis. However, there have been very few studies that examined CC area in Parkinson's disease (PD). In the present study, we aimed to determine whether there are alterations in the CC of PD. The study included 20 (9 females and 11 males) adult controls and 20 ( 8 females and 12 males) patients with PD. Structural MRI was done to both patients and controls. Dicom images were analysed using ImageJ software. Midsagittal surface area of the corpus callosum and intracranial cavity were measured using the planimetry technique. The projection area fraction (PAF) of the $\mathrm{CC}$ was measured in the midsagittal section of magnetic resonance images.The mean of midsagittal surface area of the corpus callosum and intracranial cavity in healthy subjects were $5.93 \pm 0.75 \mathrm{~cm}^{2}$ and $147.20 \pm 9.11 \mathrm{~cm}^{2}$, respectively, and were $6.26 \pm 0.75 \mathrm{~cm}^{2}$ and $151.10 \pm 13.68 \mathrm{~cm}^{2}$ for patients. The mean of the projection area fraction (PAF) for controls and patients were $4.04 \mathrm{~cm}^{2} \pm 0.54$ and 4.16 $\mathrm{cm}^{2} \pm 0.53$. There were no statistical differences between groups regarding the midsagittal surface area of the corpus callosum, intracranial cavity and PAF $(\mathrm{p} \leq 0.05)$. In the light of the literature there are few studies for the assessment of the CC in PD, the obtained data of those studies didn't show statistical significant differences between groups and gender. We conclude that the patient with PD do not have CC atrophy in contrast to other neurodegenerative diseases.

J. Exp. Clin. Med., 2014; 31:143 